\title{
Introducing Phenomenology into Fictive Motion
}

\author{
Lihong Shi \\ Foreign Language Department \\ Beijing Institute of Graphic Communication \\ Beijing, China 102600
}

\begin{abstract}
This paper aims to introduce phenomenology into fictive motion research. First, the research of Talmy, Langacker, Lakoff and Turner, Fauconnier, and Matlock on fictive motion are reviewed, whose views are popular in this field. Then, it introduces several key concepts in phenomenology to explain the fictive motion sentences: intersubectivity, affordance, intentionality, sedimentation. Intersubjectivity and affordance can be regarded as the cognitive motivations of fictive motion expressions. The introduction of phenomenological notions gives new insights into fictive motion research.
\end{abstract}

Keywords-fictive motion; phenomenology; intersubjectivity; affordance; intentionality; sedimentation

\section{INTRODUCTION}

In recent years, the linguistic phenomenon that the use of sentences with motion verbs denotes states with, at least from surface, no motions has attracted much attention of researchers in cognitive semantics. Eg:

- (1) That mountain range goes all the way from Canada to Mexico.

- (2) The road runs through the dessert.

- (3) Light shone from the sun into the cave.

- (4) He was uplifted by her smile.

In the 4 examples, motion verbs are utilized to denote the motionless objects without life such as mountain ranges, the road, and the light. Light may travel from the perspective of physics, but its motion still is beyond the human vision. This recurrent linguistic phenomenon seems universal in most languages. It was termed as fictive motion (Talmy, 2000) and subjective motion (Langacker, 1987; Matsumoto, 1996; Brandt, 2009) or abstract motion (Matlock, 2010) and NonActual Motion (Blomberg and Zlatev, 2014). This paper will follow Talmy and adopt the term fictive motion since his categorization of fictive motion is widely accepted and has been regarded as the foundation of FM research. According to Talmy, fictive motion is the cognitive bias towards dynamism (Talmy, 2000). But Langacker instead attributes the motion aspect of fictive motion expressions to the subjective motion on the part of the conceptualizer. So, different linguists pose different cognitive mechanisms for FM. This paper will review the widely accepted theories in fictive motion first and then introduces several key concepts in phenomenology to explain fictive motion sentences.

\section{FICTIVE MOTION}

As the one of the founders of cognitive semantics, Talmy was among the first researchers who has systematically explored into fictive motion. Talmy first mentioned fictive motion in his paper "Figure and ground in complex sentences" published in 1978. He thinks sentences of spatial relationships and motion events are spatial-temporal homologies (Talmy, 1978: 632). He expounded the system of spatial concepts in detail in "How language structure space" published in 1983. In 1996, Talmy divided the linguistic representations into 2 types in terms of their difference from visual representations. If the linguistic representations in the literal sense highly conform to the visual images in observers' eyes, then they are classified as factual representations. If the conformity is low, they are called fictive representation, like the utilization of motion verbs to depict the motionless state of an object. Talmy further classifies the fictive motion into 6 categories: emanation, pattern paths, frame-relative motion, advent paths, access paths and co-extension paths. The emanation can further be divided into 5 sub-categories: orientation paths, radiation paths, shadow paths, sensory paths and communication paths.

\section{A. Talmy's View}

According to Talmy, human beings have quite a number of cognitive systems like the sensory system, memory, and language etc. All the cognitive systems are not independent from other each. Instead, they are correlated and can be regarded as a continuum. All the cognitive systems can work together under the guidance the brain and they are overlapping with each other, which he terms as "ception" (Talmy, 2000). Every cognitive system has its particular features which distinguish it from others, while each has the commonalities with others. Language is just one of the cognitive systems and when the linguistic representation is not consistent with its visual perception, the discrepancy may lead to the linguistic phenomenon: fictive motion. The discrepancy between the 2 cognitive systems on the same entity does not mean the 2 systems are contradictory with each other. Rather the discrepancy is due to their different perspectives toward the object. As a result, the motion verbs are employed to depict the motionless entity, while the stationary verbs can also be utilized to describe the motion event. But there are more instances in the former, while much less in the latter, which can only exhibit human's preference for motion event rather than stationary event. 


\section{B. Langacker's View}

Langacker mainly approaches the subjective motion from the perspective of cognitive grammar. According to Langacker, constructing meaning is a process of conceptualization. Language is an important tool in depicting the factual reality and those relationships in the real world. But on many occasions, those depictions are not direct, or they are indirect, just as the conversational implicature and metaphor. More importantly, human often depict the actuality by referring to the virtuality. Fictive motion is actually the speaker's mental scanning of the motionless entity (Langacker, 1999). Compared with Talmy, Langacker further extends the subjective motion from space to conceptualization.

\section{Lakoff's View}

Lakoff's exploration into fictive motion is mainly based on conceptual metaphor. In their viewpoint, fictive motion realizes mapping across domains and it is the linguistic representation of the metaphor FORM IS MOTION, whose source domain is motion and whose target domain is shape and form. So, fictive motion is in essence a conceptual mapping to comprehend the shape and form with motion. Sometimes, the metaphor underlay is so conventional that it has fossilized in human concepts to be clearly noticed (Lakoff, 1987).

\section{Fauconnier's View}

Fauconnier explains fictive motion based on the conceptual blending theory. According to this theory, there are 4 mental spaces in human's basic concepts: 2 input spaces, a generic space, and a blending space, which make up a conceptual network. To understand metaphors or difficult concepts, the listener has to map one input space to the other and together with generic space they are blended in blending space. Through composition, completion and elaboration, a new emergent structure is produced in the blending space, which is crucial to the comprehension of linguistic phenomena.

\section{E. Matlock's View}

By carrying out different experiments, Matlock claims that fictive motion is actually the mental simulation of the motion in one's brain. His experimental results show that subjects dealing with sentences with fictive motion will use more time than those who do not, which can indirectly illustrate his point that people are simulate the motion in their brain and the simulation takes time (Matlock, 2004a; Matlock, 2004b; )

\section{THE KEY CONCEPTS IN PHENOMENOLOGY}

Phenomenology is a 20-century philosophical school founded by Edmund Husserl. It is primarily concerned with the systematic reflection and study of structure of the phenomena in the acts of consciousness. Phenomenological ideas are employed by some cognitive linguists to explore the linguistic phenomenon of fictive motion. According to Jordan Zlatev \& Johan Blomberg (2014, 2015, 2016), the fictive motion phenomenon can be more appropriately and reasonably explained with the phenomenal notions, like intersubjectivity, affordance, inentionality, and sedimentation.

\section{A. Intersubjectivity}

Intersubjectivity is a short-hand description for a variety of human interactions. It refers to the agreement people hold on a given set of meanings or the definition of the situation. It has been understood as the common sense or the shared divergence of meanings constructed by people in their interactions with each other and can be used as everyday resource to interpret the meanings of elements of social and cultural life. In phenomenology, intersubjectivity means intercorporeal, denoting the experience of one's own body as another. Husserl's embodied intersubjectivity is based on the dual nature of body: on the one hand as a internally perceived subjectivity and agency, on the other as externally perceived biological entity. This duality of body is emphasized by Husserl in his utility of two German terms to refer to body: Leib (profiling the lived aspect) and Körper (profiling the observed aspect). The lived body and the living body may coincide. The body that has been touched becomes an object to touch. The experience of one's own body as one's own subjectivity then is applied to others, which, through apperception, has constituted as subjectivity. Clearly, this transcendental condition is a precondition for one to apprehend others as fundamentally oneself.

\section{B. Affordance}

The term affordance was first developed by Gibson in 1979 and it was defined as what the environment can provide or furnish the living being. It depends on the ability of the living beings to recognize and to take advantage of it. According to Gibson, human beings tend to alter and modify the environment to better suit them. Affordance depicts the connection between perception and potential action. The key to understanding affordance is the suitability of the environment to the observer and his intentions and capabilities to utilize it. For instance, in view of a door knob, a person may think of the possibility to open the door esp. when he wants to get into or out of the door. Likewise, in perceiving a road, one may see the possibility to drive a car on the road. So, human perception may naturally relate the physical environment with their potential actions that can be carried out. Hence, the road, path, or trail in language may be connected with the potential motion of vehicles or human beings.

\section{Intentionality}

Intentionality is a term to refer to the power of the mind to represent, to stand for things, properties or state of affairs. It was identified with consciousness of something. According to Husserl, intentionality means the consciousness stretching out to the object, which indicates the simultaneity of conscious act and the object. Two terms: noesis and noema are coined by Husserl to denote real content and the ideal content of an intentional act. Noesis is real in that it is actually part of what takes place in the consciousness of the 
subject of the act. Noesis always correlates with noema. The noematic sense usually refers to the ideal meaning of an act and the noematic core as the act's referent or object as it is meant in the act. Zlatev (2010) puts them into subjective intentional act (noesis) and the (objective) intentional object (noema), respectively.

\section{Sedimentation}

Sedimentation was proposed by Husserl in his book Origin of Geometry (Husserl, 1970). He points out that in the process of conventionalization and normalization of a language, the linguistic meanings are repeated and appropriated until finally the correct form of language is accepted. During this process, the original motivation or prelinguistic experience of the language has been sedimented or buried without any trace in the language. The loss of motivation, at the same time, the gain of popularity is, according to Husserl, a double-edged knife to language.Woelert (2011, p. 119) describes this dialectic process as follows:

$\cdots$ sedimentation refers to a consolidating process of linguistic conceptualization, in the course of which the evident cognitive structures originally given in embodied sense-experience have certain "persisting linguistic acquisitions" superimposed on them (Husserl 1970b, p. 362). In particular, through sedimentation, linguistic concepts become more and more an immediately available, unquestioned (and sometimes even unquestionable) element of the language user' s conceptual repertoire.

\section{Fictive Motion And PHENOMENOLOGICAL CONCEPTS}

\section{A. Fictive Motion and Intersubjectivity}

Just as it was pointed out, intersubjectivity refers to the shared experience based on the dual nature of body: the "internally" perceived subjectivity as well as the "externally" perceived biological entity (Jordan Zlatev \& Johan Blomberg, 2016). How a human person feels as an individual towards an object could be transferred to others and at the same time be mediated by what other people think of the same object. Thus, an individual could also perceive an entity from the perspective of others which may give rise to the following fictive motion sentences:

- (5) The enemy can see us from where they are positioned (Talmy 2000, p. 115)

- (6) She can see you from her window.

In (5) and (6), the view of the speaker has changed from his own to his enemy looking at himself. It is human's imagination and sedimented experience that help to achieve that. Intersubectivity, in this sense, can be regarded as one the cognitive motivations of fictive motion expressions.

\section{B. Fictive Motion and Affordance}

Affordance connects the perception with the potential act. Just as the following examples can show:
- (7) The road goes through the forest.

- (8) The trail rises steeply near the summit.

In these 2 examples, the possibility that the road and the trail can afford the motion of a vehicle will naturally make the observer associate the motion with the road and trail. The motion property of the vehicle is therefore transferred to the road and trail, which leads to the appearance of the fictive motion sentences. This also conforms to the economy principle of language.

\section{Fictive Motion and Intentionality} Eg.

Intentionality indicates the directedness of consciousness.

- (9) The enemy can see us from his position.

- (10) I must look tall to her.

In (9) and (10), there are actually no motions. What happens is just a change of vantage point. The speaker intentionally changes his perspective to his enemy, which can also be understood as intentional directing one's attention to an object. Intentionality does not motivate the fictive motion sentences but give clearer picture of the deeper connection.

\section{Fictive Motion and Sedimentation}

As it is previously said, sedimenation refers to the linguistic phenomenon that the original prelinguistic experience and motivation are covered or lost during the process of conceptualization and normalization. Verbs like uplift, and run through etc have buried their original motivational experience and only the more abstract meanings are sedimented, as shown by (11) and (12).

- (11) He was uplifted by her smile.

- (12) The road runs through the dessert.

\section{CONCLUSION}

Husserl's phenomenology provides a new perspective to fictive motion expressions. Intersubjectivity refers to the shared experience perceived by others, whose transcendent nature lends itself a cognitive motivation to fictive motion sentences. Affordance points out the connection between the perception and the potential action, which is also a cognitive motivation of fictive motion expressions. Intentionality demonstrates the correlation between the consciousness in the subject of intentional act and the object. Due to the sedimenation in language, the original motivation of linguistic forms is covered up, but the entrenchment is gained. Those key phenomenological concepts have deepened the understanding of fictive motion sentences. In the future research, empirical research is needed to prove the theory.

\section{ACKNOWLEDGEMENT}

This research is sponsored by General Project of Beijing Municipal Education Commission (No. 
SQSM201710015004) and 2016 Scientific Research Project of Beijing Institute of Graphic Communication (No. 20190116002/034).

\section{REFERENCES}

[1] Blomberg, Johan \& Jordan Zlatev. 2014. Actual and non-actual motion: Why experientialist semantics needs phenomenology (and vice versa). Phenomenology and the Cognitive Sciences, 13(3), 395418.

[2] Blomberg, Johan. 2015. The expression of non-actual motion in Swedish, French and Thai. Cognitive Linguistics, 26(4), 657-696.

[3] Bohnemeyer, Juergen. 2010. Path, fictive motion, and time relations. In Barbara, Malt \& Philip Wolff (eds.), Words and the Mind: How Words Capture Human Experience, 111 - 137. Oxford: Oxford University Press.

[4] Brandt, L. 2009. Subjectivity in the act of representing: The case for subjective motion and change. Phenomenology and the Cognitive Sciences, 8(4), 573-601.

[5] Husserl, Edmund. [1936]1970. The Crisis of European Sciences and Transcendental Phenomenology. Evanston, IL: Northwestern University Press.

[6] Johnson, Mark. 2010. Metaphor and cognition. In Gallagher \& Schmicking (eds.), $401-414$.

[7] Lakoff, G. 1987. Women, fire, and dangerous things: What categories reveal about the mind. Chicago: University of Chicago Press.

[8] Lakoff, George \& Mark Johnson. 1980. Metaphors we Live by. Chicago, IL: University of Chicago Press.

[9] Lakoff, George \& Mark Johnson. 1999. Philosophy in the Flesh: The Embodied Mind and its Challenge to Western Thought. New York: Basic Books.

[10] Langacker, Ronald W. 1987. Foundations of Cognitive Grammar: Theoretical Prerequisites. Stanford, CA: Stanford University Press.

[11] Langacker, Ronald W. 2006. Subjectification, grammaticization, and conceptual archetypes. In Angeliki Athanasiadou, Costas Canakis \& Bert Cornille (eds.), Subjectification: Various Paths to Subjectivity, 17-41. The Hague: Mouton de Gruyter.

[12] Mandler, Jean. 2004. The Foundations of Mind: Origins of Conceptual Thought. Oxford: Oxford University Press.

[13] Matlock, Teenie. 2004a. Fictive motion as cognitive simulation. Memory \& Cognition, 32(8): 1389-1400.

[14] Matlock, Teenie. 2004b. The conceptual motivation of fictive motion. In Günter Radden \& Klaus-Uwe Panther (eds.), Studies in linguistic motivation, 221-248. Berlin: Mouton de Gruyter.

[15] Matlock, Teenie. 2010. Abstract motion is no longer abstract. Language and Cognition, 2(2), 243-260.

[16] Matsumoto, Y . 1996. Subjective motion and English and Japanese verbs . Cognitive Linguistics ,7 (2), 183-226.

[17] Merleau-Ponty, Maurice. [1945]1962. Phenomenology of Perception. London: Routledge.

[18] Talmy, Len. 2000. Toward a Cognitive Semantics, vol. 1. Cambridge, MA: MIT Press.

[19] Woelert, P. 2011. Human cognition, space, and the sedimentation of meaning. Phenomenology and the Cognitive Sciences, 10(1), 113-137.

[20] Zahavi, Dan. 2001. Beyond empathy: Phenomenological approaches to intersubjectivity. Journal of Consciousness Studies 8(5-6), 151-167.

[21] Zahavi, Dan. 2003. Husserl's Phenomenology. Stanford, CA: Stanford University Press.

[22] Zahavi, Dan. 2014. Self and Other: Exploring Subjectivity, Empathy, and Shame. Oxford: Oxford University Press. 